\title{
COMPOUNDING AND PROCESSING HYDRO-BIODEGRADABLE PLASTIC FILMS FOR PLASTIC WASTE REDUCTION. PART I: PROCESSING CONDITIONS AND ENVIRONMENTAL PERFORMANCE AGAINST PLASTIC SOLID WASTE
}

\author{
HAJAR JAWAD KARAM, MASUMAH AL-QASSIMI, MAJED HAMEED AL-WADI, \\ AISHA ABDULLAH AL-ROWAIH, ABDUL SALAM AL-HAZZA'A \& SULTAN MAJED AL-SALEM \\ Environment \& Life Sciences Research Centre (ELSRC), Kuwait Institute for Scientific Research (KISR), Kuwait
}

\begin{abstract}
The reliance on conventional polymeric materials derived from petrochemical sources, has been associated with various environmental burdens and stressors that are well documented. These are namely associated with the overall carbon print of plastics conversion and an overwhelming accumulation of solid waste; which on the other hand is associated with soil and water aquifers poisoning in many regions the world over. In this work; and in an effort to develop a polymeric blend that can sustain itself in terms of mechanical integrity, thermoplastic starch polyester was converted with virgin linear low density polyethylene (LLDPE) and a plastic solid waste (PSW) component retrieved from municipal sources. The objective in this communication is to study the effect of different compounding conditions on the resulting blends which were characterized using scanning electron microscopy (SEM), mechanical profiling in accordance with ASTM 882-12 and physical-optical properties determination. The blends were originally prepared using single screw extrusion (SSE), twin screw extrusion (TSE) and blown-filming, to determine which of the processes are more reliable for industrial bulk production purposes in the future to establish a plastic conversion line suitable for biodegradable plastic film conversion.
\end{abstract}

Keywords: biodegradation, polyester, starch, polymer waste, waste management.

\section{INTRODUCTION}

Due to the environmental concerns associated with the disposal of plastic solid waste (PSW), the development of a new class of materials becomes a necessity rather than a luxury. Biodegradable plastics presents itself as such, and it has proven itself as an effective measure against conventional plastics. Comprehensive assessments of biodegradable polymers applications and current developments were reviewed previously by Amass et al. [1]. Emadian et al. [2] reported that biodegradation cannot lead to a complete disappearance of the material. The colonisation of microorganism on the plastic occurs when materials are exposed to the appropriate conditions of soil and humidity. Chiellini et al. [3] has also provided an overview of the degradable polymers in agricultural applications. Orhan and Büyükgüngör [4] tested the biodegradability of polyethylene (PE) bags containing $12 \%$ by weight of starch. They reported that PE plastics build-up in the environment is at a rate of 25 million tons per year. Ohtaki and Nakasaki [5] examined the degradability of several biodegradable plastics under controlled composting conditions and concluded that the degradability of 8 plastic ranged from a few percentage points to approximately $65 \%$ over the 8 days composting period at $50^{\circ} \mathrm{C}$. Studies of polymer degradation during their lifecycle have shown that there are usually two main steps involved: abiotic and biotic degradation. Abiotic degradation involves the degradation of the polymeric content due to environmental exposure and is accompanied by microbial colonisation (biotic degradation) [6]. 
Biodegradation at chemical level is initiated by containing a carbonyl functional group $(\mathrm{C}=\mathrm{O})$ within a chemical chain. Hydro-biodegradable materials contain carbonyl groups, which break down with heat and moisture. A $100 \%$ of such material is therefore classified on its own as biodegradable. Oxo-biodegradable plastics, do not contain carbonyl groups making it essential to introduce other additives which will change their chemical properties and accelerate the oxidation process leading to biodegradation of the material. Reddy et al. [7] revealed that biodegradables can mitigate harmful pollutants from leaching into surrounding environments, such as chlorinated compounds and toxins. The reader is referred to our earlier work on the biodegradability of oxo-biodegradables in arid climates as well [8]-[10].

Montagna et al. [11] also reported the use of different pro-degradant materials to enhance polymers biodegradability and showed the influence of an organic pro-degradant on PP under the two different environmental conditions (abiotic and biotic). According to literature, various characterisation methods such as spectroscopy (FTIR), mechanical testing [12], [13], and thermal analysis (TGA and DSC) [14] have been used to assess the composition of waste [15] as a result of their susceptibility to changes in material properties. FTIR spectroscopy is found to be the most effective and sensible technique for measuring polymer degradation [15]. In this article which is the first part of a two series communication, we present the compounding and basic characterisation of various biodegradable blends originating from virgin linear low density polyethylene (LLDPE) and PSW, enhanced with a prod-degradant and a thermoplastic starch (TPS) resin.

\section{EXPERIMENTAL}

Commercial grade LLDPE (EFDC-7050) was used as received in a pellet form with a reported density of $0.918 \mathrm{~g} \mathrm{~cm}^{-3}$ [8]. The LLDPE polymer was compounded with a $3 \mathrm{wt} . \%$ ECOVIO $^{\circledR}$ (TPS) resin and by the same amount with a PDQ-M Willow Ridge Plastics (Inc.) pro-degradant chemical, using three different techniques that are standardised in the industry of plastics conversion. These techniques are namely, (a) single screw extrusion (SSE), (b) twin screw extrusion (TSE), and (c) blow-filming (BF) which are the most common among commercial film production lines, and have been chosen to study the effect of processing and melting on the materials. SSE was performed using a Dolci extruder (L/D ratio $1 / 28$ ) using $10 \mathrm{~kg}$ as master batch mix. The blends with TPS were conducted in the same mix ratios as the oxo-additives. Mixing with palletized PSW was also conducted in the same blend ration of $3 \mathrm{wt} . \%$. Furthermore, BF was conducted with the same formulations aforementioned using a Windsor blown-film coupled with an L/D (1/28) SSE operated under 6 bars of pressure. TSE was performed using a Kung Hsing operated in co-rotation with a maximum speed of 75 RPM maintained throughout the experimental work. The TPS samples were extruded in a standalone Brabender SSE which was used in the compounding process of the samples. All samples were extruded as sheets of $100 \mu \mathrm{m}$ thickness meeting standard market specifications and as an average of major film applications. Mechanical properties were studied following test protocol of ASTM 882 using a Tinius Olsen Universal Testing Machine (UTM) machine as depicted previously in Al-Salem et al. [8]. The optical and physical properties of the samples were evaluated using the PCE-CSM3 colorimeter following ASTM D 2244 protocol to measure colour parameters. The tests were used to establish the colour parameters for light/dark $\left(L^{*}\right)$, red/green $\left(a^{*}\right)$, and yellow/blue $\left(b^{*}\right)$. The average readings of the specimen are reported. The haze (\%) and light transmission (\%) of the samples were determined using a MF709 (spherical) haze meter (model BS 2782) following ASTM D 1003 similar the methods applied in past works [8], [16]. This provided an estimate of the crystalinity change and 
amorphous region loss within the polymer matrix to determine the pre-degradation behaviour. Replicates of the specimens were tested for haze (\%) and light transmission (\%) and the average of the readings were reported.

\section{RESULTS AND DISCUSSION}

Table 1 depicts a sample of the mechanical properties estimated in this work. Typically, stress values are not related to the waste content in the blend [17]. Due to polymer films processing conditions, the change in the amorphous region affects the stress at break, which results from the heating cycles at compounding stages [18]. Stress at break was measured for the LLDPE and its blends and was compared with PSW. The effect of the compounding technique on stress at break, as well as, additive content was evident in the stress at break values (Fig. 1). SSE compounding gave the highest stress at break values for the LLDPE and PSW blends with and without PDQ-M. On the other hand, LLDPE/TPS blend exhibited the highest stress when compounded using TSE. Overall, the presence of the additives has affected the stress at break of the LLDPE polymer only. The PDQ-M additive allowed LLDPE blends to withstand the highest stress at break values compared to the pure LLDPE. The PSW, PSW/PDQ-M and PSW/TPS samples showed the same mechanical behaviour, i.e. they have similar stress at peak values for all compounding techniques. In general, the reported stress at break for pure LLDPE is several folds higher than that reported earlier in literature. TPS is a low-cost biodegradable polymer that can offer undesirable mechanical properties [19]. Adding TPS to the blends has been found to reduce the modulus and tensile strength of the Young but generally speaking this impact becomes greater as the TPS content increases [20]. The TPS sample reported the highest stress at break value (373 MPa) compared to all samples tested. This indicates that on a molecular level, the crystallinity of the TPS formulation is higher than the other examined blends, which is due to it exhibiting a higher stress at break as observed in Fig. 1. Again, the reported TPS stress at break values were several folds higher than those reported in literature [20], [21]. A study of particular interest is that of Shan et al. [22] which investigated the change in tensile stress over strain for a mixture of LDPE and two types of PP, namely homogeneous PP (PPH) and PP block-copolymer (PPC), over the full range of blend composition. The blends were compounded in a TSE and then injection moulded into test specimens. The mechanical properties of the blends were reported to show that pure LDPE had the lowest stress point (about $11 \mathrm{MPa}$ ) compared to its blends with PP.

Table 1: Sample of the mechanical properties estimated in this work showing the mechanical tensile pull properties of the blow film samples.

\begin{tabular}{|l|c|c|c|c|}
\hline $\begin{array}{l}\text { Material/Blend } \\
\text { (wt.\%/wt.\%) }\end{array}$ & $\begin{array}{c}\text { Young's Modulus } \\
(\mathrm{MPa})\end{array}$ & $\begin{array}{c}\text { Stress at } \\
\text { break } \\
(\mathrm{MPa})\end{array}$ & $\begin{array}{c}\text { Strain at } \\
\text { break } \\
(\%)\end{array}$ & $\begin{array}{c}\text { Strain at } \\
\text { break } \\
(\mathrm{N})\end{array}$ \\
\hline LLDPE (100) & $5048 \pm 1783.94$ & $291 \pm 11.49$ & $922 \pm 20.30$ & $29.1 \pm 1.15$ \\
\hline LLDPE/PDQ-M (97/3) & $3333 \pm 740.14$ & $305 \pm 15.12$ & $939 \pm 28.44$ & $30.5 \pm 1.51$ \\
\hline LLDPE/TPS (97/3) & $3697 \pm 254.46$ & $276 \pm 6.31$ & $887 \pm 21.51$ & $27.6 \pm 0.63$ \\
\hline PSW (100) & $3891 \pm 199.90$ & $194 \pm 5.99$ & $782 \pm 20.80$ & $19.4 \pm 0.60$ \\
\hline PSW/PDQ-M (97/3) & $3718 \pm 269.67$ & $186 \pm 15.25$ & $749 \pm 50.54$ & $18.6 \pm 1.52$ \\
\hline PSW/TPS (97/3) & $3951 \pm 181.57$ & $184 \pm 7.02$ & $752 \pm 45.17$ & $18.4 \pm 0.70$ \\
\hline
\end{tabular}




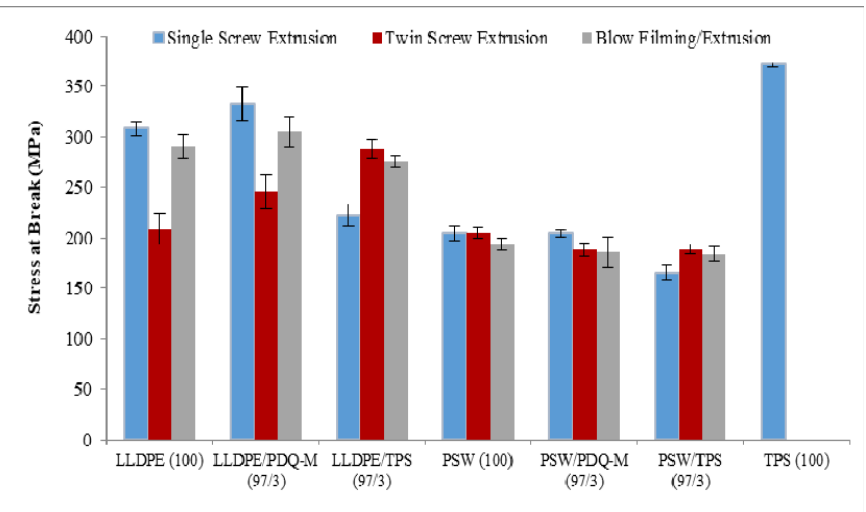

Figure 1: $\quad$ Stress at Bre |AK (MPa) measured for the compounded LLDPE and PSW films without and with TPS and PDQ-M.

The mechanical behaviour of the graphite nanophalates/LDPE manufactured with compression moulding and blown film extrusion technologies, was investigated by Carotenuto et al. [23]. The pure LDPE was found to be capable to stand extension up to $600 \%$ by activating necking and cold-drawing mechanisms. In BF, mechanical properties in the machined direction (MD) and the transverse direction (TD) were tested. In the transverse direction the unreinforced LDPE in the blown extrusion process exhibited a behaviour that is very similar to that observed for compression moulded samples. The polymeric chains' orientation effect was clearly visible in the Machined Direction (MD) sample curve, where LDPE behaved more like a brittle material, hitting higher tensile strength values $(22 \mathrm{MPa})$ but a lower maximum pressure. However, the maximum strain reached only $300 \%$ which was almost twice for previously tested LDPE. Similar results were reported by Guichon et al. [24]. Another important consideration was the Young's modulus, which was not influenced by the transverse and the machined direction (180 MPa for TD and $185 \mathrm{MPa}$ for MD), which means that the chain orientation mainly affected the necking and re-crystallisation phases and not the elasticity of polymers. Mechanical properties in terms of compressive response of LDPE were investigated across a range of strain rates and temperatures [25]. The LDPE plate samples were machined in the throughthickness direction, with a few experiments conducted in the two orthogonal directions. The LDPE stress-strain curve revealed an initial linear elastic region followed by a non-linear transition to yield, followed by strain softening and strain hardening afterwards. As predicted in most polymers, LDPE is showed an increase in stress with higher strain rate or lower temperature. LDPE stress-strain response was qualitatively similar to Omar et al. [26] LDPE response.

Strain at break (\%) was estimated and depicted in Fig. 2. A clear variation is seen in relation to the additive content in the measured stain at break values for all the LLDPE formulations using the different compounding techniques. Furthermore, pure LLDPE and LLDPE-PDQ-M samples compounded in SEE exhibited the highest change in terms of strain when compared to their compounded samples using TSE and BF. This is in contrast to LLDPE-TPS sample compounded using SSE where a clear drop is noted in its strain value. This can be attributed, to the immiscibility on a physical level of the polymeric blend using this compounding technique. For the PSW and its blends it can be seen that similar strain values were maintained for all compounding techniques. This shows that an amount 
of $3 \mathrm{wt} \%$ of additive could be added to PSW samples with no effect on the product integrity. All of the samples tested in this study revealed higher strain at break values than TPS, indicating superiority of the blends over the TPS material. All of the PSW samples measured in this study showed relatively high strain at break values in comparison to the pure LLDPE and its blends, proving clear superiority of the waste blends over the pure polymer from an economical and environmental point of view.

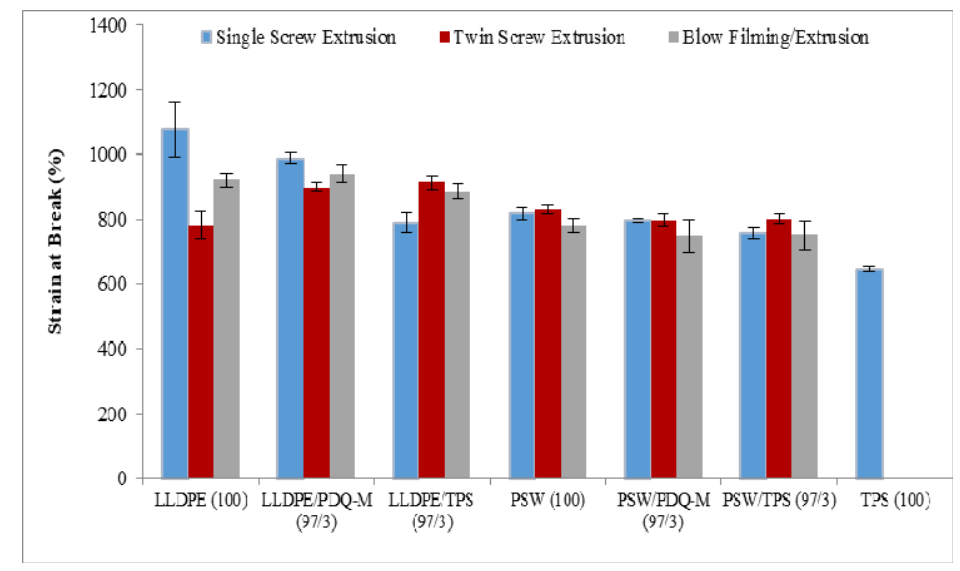

Figure 2: Strain at break (\%) measured for the compounded LLDPE and PSW films without and with TPS and PDQ-M.

Colour parameters were measured and summarised in Table 2. The effect of compounding techniques on the blends in terms of the difference in the measured colour parameters was evident in SSE samples. LLDPE/PDQ-M blend compounded in SSE were lightest in colour and more yellow compared to LLDPE and LLDPE-TPS. Using the same compounding technique also, PSW had the highest lightness value compared to its blends. Amongst all compounded samples using SSE, TPS had the highest lightness, while L* values of its blends declined by increasing LLDPE and PSW content (97 wt.\%) in the films. Lightness recorded for pure LLDPE, PSW and their blends compounded in TSE and BF were relatively within the same range (Table 2). Overall, the LLDPE and PSW films did not have the same $\mathrm{L}^{*}$ and $\mathrm{a}^{*}$ values in all compounding techniques. The same was also observed for their blends with PDQ-M and TPS. The $\mathrm{a}^{*}$ values which stand for redness (or greenness) in colour space were insignificant, and even for films compounded in TSE and BF they were near zero. For $b^{*}$ values, PSW/TPS blend and PSW films had the highest yellowness levels in SSE and BF, respectively. The LLDPE/PDQ-M blend compounded in TSE had the most yellowness level amongst all compounded films. In general, lightness $\left(\mathrm{L}^{*}\right)$ was in line with the general colour measurement theory, since transparent and achromatic films should have high lightness and minimum colour space values of a $*$ and $\mathrm{b}^{*}$. Al-Salem et al. [27], [28] also tested colour parameters of control unexposed LLDPE/Waste $(100 / 0)$ sample extruded using a single screw extruder $(\mathrm{L} / \mathrm{D}=30)$ and film blowing machine. The reported $\mathrm{L}^{*}, \mathrm{a}^{*}$ and $\mathrm{b}^{*}$ values were $29.0,-0.4$, and -3.5 , respectively. These were slightly different from those of the pure LLDPE colour parameters reported in the study. Al-Salem et al. [28] also concluded that there was no change in colour parameters with respect to DHT. 
Table 2: Colour parameters compounded LLDPE and PSW films (with and without TPS and PDQ-M additives).

\begin{tabular}{|l|c|c|c|}
\hline Material/Blend (wt.\%/wt.\%) & L* & $\mathrm{a}^{*}$ & $\mathrm{~b}^{*}$ \\
\hline \multicolumn{2}{|c|}{ Single screw extrusion } \\
\hline LLDPE (100/0) & $35.06 \pm 0.55$ & $-1.16 \pm 0.07$ & $0.25 \pm 0.28$ \\
\hline LLDPE/PDQ-M (97/3) & $44.50 \pm 1.74$ & $-1.43 \pm 0.34$ & $0.90 \pm 0.43$ \\
\hline LLDPE/TPS (97/3) & $40.29 \pm 0.33$ & $-1.22 \pm 0.13$ & $0.28 \pm 0.14$ \\
\hline PSW (100/0) & $37.92 \pm 0.67$ & $-1.31 \pm 0.12$ & $0.57 \pm 0.41$ \\
\hline PSW/PDQ-M (97/3) & $23.93 \pm 0.43$ & $-1.47 \pm 0.13$ & $0.18 \pm 0.05$ \\
\hline PSW/TPS (97/3) & $34.60 \pm 0.95$ & $-1.17 \pm 0.41$ & $3.48 \pm 0.37$ \\
\hline TPS (100/0) & $72.49 \pm 0.16$ & $-2.33 \pm 0.01$ & $-3.91 \pm 0.07$ \\
\hline \multicolumn{4}{|c|}{ Twin screw extrusion } \\
\hline LLDPE (100) & $27.64 \pm 0.39$ & $0.22 \pm 0.06$ & $2.40 \pm 0.22$ \\
\hline LLDPE/PDQ-M (97/3) & $28.58 \pm 0.16$ & $0.40 \pm 0.05$ & $3.59 \pm 0.18$ \\
\hline LLDPE/TPS (97/3) & $23.86 \pm 0.06$ & $-1.25 \pm 0.13$ & $0.14 \pm 0.22$ \\
\hline PSW (100) & $31.50 \pm 0.11$ & $-0.32 \pm 0.04$ & $0.56 \pm 0.13$ \\
\hline PSW/PDQ-M (97/3) & $27.46 \pm 0.12$ & $-0.31 \pm 0.11$ & $0.37 \pm 0.12$ \\
\hline PSW/TPS (97/3) & $32.37 \pm 0.15$ & $-0.68 \pm 0.07$ & $-0.72 \pm 0.19$ \\
\hline \multicolumn{4}{|c|}{ Blow filming/extrusion } \\
\hline LLDPE (100) & $30.90 \pm 0.18$ & $-0.09 \pm 0.03$ & $0.44 \pm 0.14$ \\
\hline LLDPE/PDQ-M (97/3) & $29.73 \pm 0.11$ & $0.06 \pm 0.03$ & $1.36 \pm 0.08$ \\
\hline LLDPE/TPS (97/3) & $26.32 \pm 0.13$ & $-0.42 \pm 0.09$ & $0.63 \pm 0.32$ \\
\hline PSW (100) & $27.54 \pm 0.18$ & $0.22 \pm 0.09$ & $2.08 \pm 0.64$ \\
\hline PSW/PDQ-M (97/3) & $31.69 \pm 0.07$ & $0.27 \pm 0.01$ & $1.57 \pm 0.02$ \\
\hline PSW/TPS (97/3) & $31.65 \pm 0.17$ & $0.01 \pm 0.00$ & $0.66 \pm 0.63$ \\
\hline
\end{tabular}

Light transmission (\%) values were measured for LLDPE and PSW blends and are shown in Fig. 3. All pure samples and their blends showed similar transparency characteristics in comparison with TPS. Samples containing 97 wt.\% LLDPE and PSW did not lose their transparency more rapidly because of the low percentage of additives in the blends. It is generally ideal for the packaging industry to manufacture films with low hazel and high gloss when the product does not need light protection [29]. Factors that can influence haze are the degree of crystallisation and/or crystal structure, and the time of polymers relaxation [30]. Higher relaxation time allows the crystallisation to occur under the influence of stress elongation, allowing the crystalline structures to be small, thin and oriented (lower haze and higher gloss) [31]. In addition, the loss of amorphous regions in polyolefins leads to hazy specimens; this was reported for TPS and its blends (LLDPE/PDQ-M and PSW/TPS) and is shown in Fig. 4. Pure LLDPE and its blends showed comparatively similar trend amongst all three compounding techniques indicating the dependency of haze (\%) on the additive presence and the compounding technique applied. The LLDPE blends showed a clear shift in haze values when compared to the pure LLDPE. The same was also observed for PSW and its blends (PSW/PDQ-M and PSW/TPS). The virgin LLDPE proved tested by Al-Salem et al. [27] to be hazier its other blends with waste. The reported Haze $\%$ and Light Transmission $\%$ of unexposed virgin LLDPE (100) were $42 \%$ and $91.5 \%$, respectively. The Haze $\%$ value was higher than that reported in the study for all LLDPE samples. The light transmission on the other hand was in agreement with that reported by Al-Salem et al. [27] (91.5\%). Al-Salem et al. [27] also reported a notable decrease in haze measurement as the waste content increased 
and light transmission showed a gradual decrease with exposure time. In addition, Al-Salem et al. [28] reported a decrease in Haze \% and light transmission\% of the virgin LLDPE/waste blends $(100 / 0,90 / 10,75 / 25,50 / 50,75 / 25$, and 10/90), compounded using single screw extruder $(L / D=30)$, with the increase in waste content due to the lack of miscibility between constituting polymers. The sensitivity of colour parameters to waste content was not evident in this study as seen in Fig. 4. The haze $\%$ and light transmission $\%$ were measured for unexposed LLDPE/waste (100/0) and (0/100) blends extruded, and blown using a single screw extruder (Tecnova, $\mathrm{L} / \mathrm{D}=30$ ) as part of the study conducted by Al-Salem et al. [8]. The study reported LLDPE/waste (100/0) haze\% and light transmission \% values of $41.27 \pm 3.1$ and $91.48 \pm 0.09$, respectively. The reported haze $\%$ and light transmission $\%$ values for LLDPE/waste $(0 / 100)$ blend were $24 \pm 0.32$ and $90.60 \pm 0.08$, respectively.

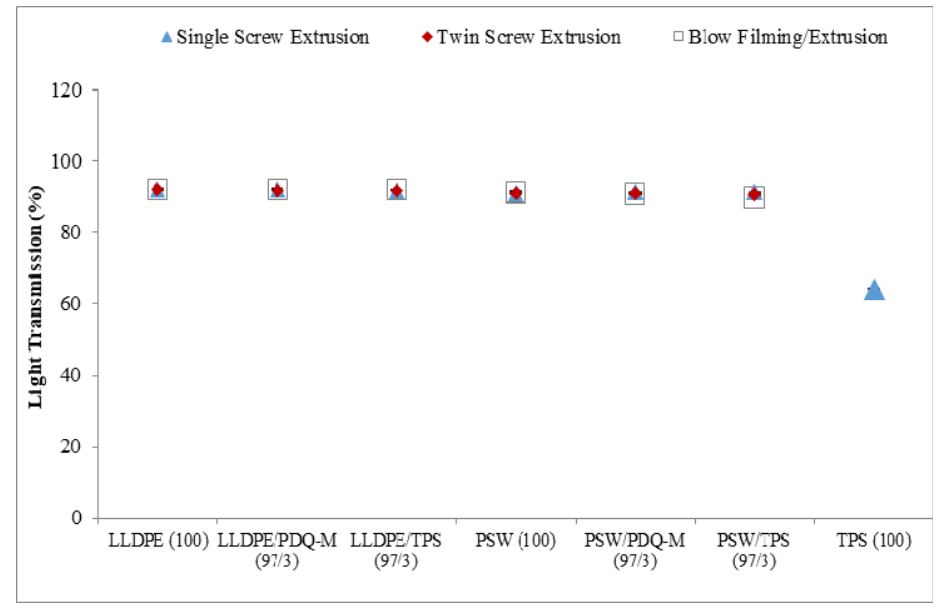

Figure 3: Light transmission (\%) of compounded LLDPE and PSW films without and with TPS and PDQ-M.

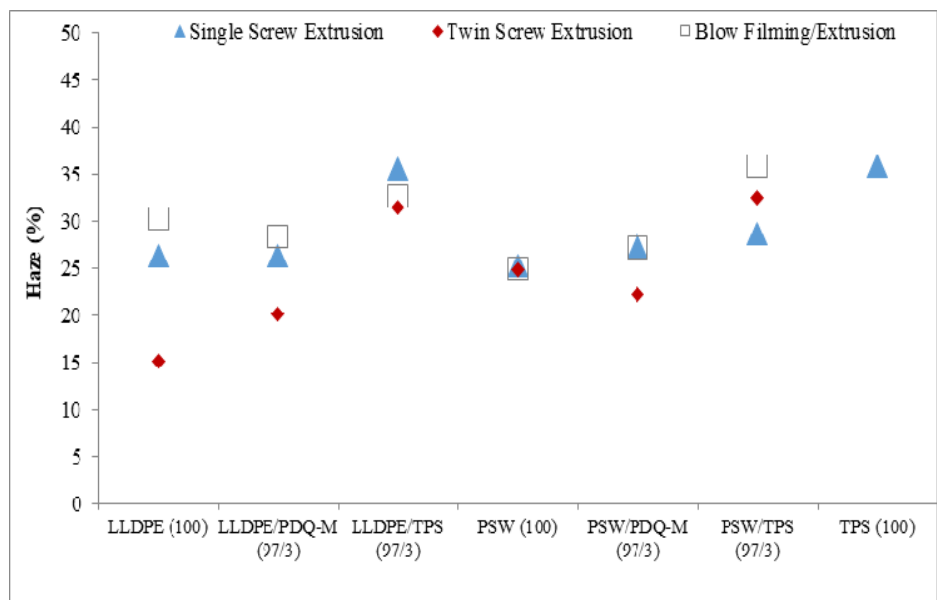

Figure 4: Haze (\%) of compounded LLDPE and PSW films without and with TPS and PDQ-M. 
It should be highlighted at this stage that oxo-biodegradables were criticised as of late for the possibility of environmental pollution (due to chemicals/toxics release to surrounding environment) and contributing to the overall microplastic (MP) release. These issues are related to oxo-biodegradables fragmentation in open environments and landfill conditions, as previously depicted in the EU Directive 94/62/EC [32]. Oxo-biodegradables are also known to be non-compostable materials, unlike hydro-biodegradables investigated in the research presented in this article. Combined with the presented efforts, and following previous recycling and biodegradation of plastics efforts in the region and its impact on the environment [9], [27], [33]-[36] the promotion of hydro-biodegradable plastics presents itself as a viable environmental solution. The execution of landfill burial experiments and following the same methodology for investigating the impact of landfill conditions on hydro and oxo-biodegradables presented elsewhere [8], [36] will also be part of this major research project in the near future that can deliver a more realistic assessment of environmental impact of such materials.

\section{CONCLUSION}

Formulated blends of virgin linear low density polyethylene (LLDPE) and plastic solid waste (PSW) with pro-degradant additive and starch based resin, were studied for their mechanical integrity and physical characteristics. All blends were in-line with past efforts characterising the mechanical integrity of market products which indicates their applicability to be mass produced as a biodegradable plastic for local markets. The compounding technique showed an immense impact on the stress at break of the blend. Single screw extrusion resulted in the highest value for the stress at break namely for the LLDPE and PSW blend. On the other hand, LLDPE/TPS blend exhibited the highest stress when compounded using TSE. It is therefore recommended to produce such blends with the aforementioned technique to meet certain demands and specifications of the market based on consumer demands. The change in mechanical properties could be attributed to the heating loop power and amount of shear applied due to the screw configuration. Starch based resin was also the haziest amongst sample produced in this work. However, the blending using twin screw extrusion showed that samples produced with this technique had the lowest haze (\%) due to the high blending resulting from the twin screw configuration. There was no apparent impact with colour parameters light transmission between all samples.

\section{ACKNOWLEDGEMENTS}

The authors are grateful to the Kuwait Institute for Scientific Research (KISR) for supporting the activities of project EM065K. We acknowledge the financial support given by the Kuwait Foundation for the Advancement of Sciences (KFAS) towards the scientific mission to deliver the oral presentation of this communication.

\section{REFERENCES}

[1] Amass, W., Amass, A. \& Tighe, B., A review of biodegradable polymers: uses, current developments in the synthesis and characterization of biodegradable polyesters, blends of biodegradable polymers and recent advances in biodegradation studies. Polym Int, 47, pp. 89-144, 1998.

[2] Emadian, S.M., Onay, T.T. \& Demirel, B., Biodegradation of bioplastics in natural environments. Waste Management, 59, pp. 526-536, 2017.

[3] Chiellini, E., Cinelli, P., D`Antone, S. \& Ivanova, S.V., Environmentally degradable polymeric materials (EDPM) in agricultural applications: An overview. Polimery, 47, pp. 21-27, 2002. 
[4] Orhan, Y. \& Büyükgüngör, H., Enhancement of biodegradability of disposable polyethylene in controlled biological soil. Int. Biodet. Biodegrad., 45, pp. 49-55, 2000.

[5] Ohtaki, A. \& Nakasaki, K., Ultimate degradability of various kinds of biodegradable plastics under controlled composting conditions. Waste Manage. Res., 18, 2000.

[6] Gomes, L.B., Klein, J.M., Brandalise, R.N., Zeni, M., Zoppas, B.C. \& Grisa, A.M.C., Study of oxo-biodegradable polyethylene degradation in simulated soil. Mat. Res., 17, 2014. https://doi.org/10.1590/1516-1439.224713.

[7] Reddy, P.S., Subbaiah, G.V. \& Subbaiah, H.V., Effect of plastic pollution on environment. Environ. Sci., 2014. https://www.semanticscholar.org/paper/EFFECTOF-PLASTIC-POLLUTION-ON-ENVIRONMENT-Reddy-Subbaiah/5c14101346a 3684bcaa8289331a9c38abe5f8a6f.

[8] Al-Salem, S., Al-Hazza'a, A., Karam, H., Al-Wadi, M., Al-Dhafeeri, A. \& AlRowaih, A., Insights into the evaluation of the abiotic and biotic degradation rate of commercial pro-oxidant filled polyethylene (PE) thin films. J. Environ. Manage, 250, 109475, 2019.

[9] Al-Salem, S.M., Sultan, H.H., Karam, H.J. \& Al-Dhafeeri, A.T., Determination of biodegradation rate of commercial oxo-biodegradable polyethylene film products using ASTM D 5988. J. of Polym. Res., 26(7), p. 157, 2019.

[10] Al-Salem, S.M. et al., Thermal response and degressive reaction study of oxobiodegradable plastic products exposed to various degradation media. Int. J. Polym. Sci., 9612813, 2019.

[11] Montagna, L.S., de Camargo Forte, M.M. \& Santana, R.M.C., Induced degradation of polypropylene with an organic pro-degradant additive. J. Mater. Sci. Eng., A3, pp. 123-131, 2013.

[12] Ashori, A. \& Nourbakhsh, A., Characteristics of wood-fiber plastic composites made of recycled materials. Waste Manage., 29, pp. 1291-1295, 2009.

[13] Vajna, B. et al., Complex analysis of car shredder light fraction, Open Waste Manage. J., 3, pp. 46-55, 2010.

[14] García M.T., Gracia I., de Lucas G.D.A. \& Rodríguez J.F., Study of the solubility and stability of polystyrene wastes in a dissolution recycling process, Waste Manage., 29, pp. 1814-1818, 2009.

[15] Vilaplana, F. \& Karlsson, S., Quality concepts for the improved use of recycled polymeric materials: A review. Macro Mater Eng, 293, pp. 274-297, 2008.

[16] Al-Salem, S.M., Influence of natural and accelerated weathering on various formulations of linear low density polyethylene (LLDPE) films. Mater. Design, 50, pp. 1729-1736, 2009.

[17] Elzubair, A. \& Suarez, J.C.M., Mechanical behavior of recycled polyethylene/piassava fiber composites. Mater. Sci. Eng. A, 557, pp. 29-35, 2012.

[18] Ha, K.H. \& Kim, M.S., Application to refrigerator plastics by mechanical recycling from polypropylene in waste-appliances. Mater. Des., 34, pp. 252-257, 2012.

[19] Oliveira, T.A., Oliveira, R.R., Barbosa, R., Azevedo, J.B. \& Alves, T.S., Effect of reprocessing cycles on the degradation of PP/PBAT-thermoplastic starch blends. Carbohyd. Polym., 168, pp. 52-60, 2017.

[20] Berruezo, M., Ludueña, L.N., Rodriguez, E. \& Alvarez, V.A., Preparation and characterization of polystyrene/starch blends for packaging applications. J. Plastic Film Sheet, 30, 2014. 
[21] Pang, M.M., Pun, M.Y. \& Ishak, Z.A.M., Thermal, mechanical, and morphological characterization of biobased thermoplastic starch from agricultural waste/polypropylene blends. Polym. Eng. Sci., 54, pp. 1357-1365, 2014.

[22] Shan, H., White, J.L. \& DeGroot, A.W., Comparison of crystallization and melting characteristics of quiescent and melt-spun poly(ethylene-co-octene) copolymers. Int. J. Polym. Anal. Charact., 12, pp. 231-249, 2007.

[23] Carotenuto, G. et al., Mechanical properties of low-density polyethylene filled by graphite nanoplatelets. Nanotech, 23, 2012. https://iopscience.iop.org/article/10.1088/0957-4484/23/48/485705/meta

[24] Guichon, O., Séguéla, R., David, L. \& Vigier, G., Influence of the molecular architecture of low-density polyethylene on the texture and mechanical properties of blown films. J. Polym. Sci. B Polym. Physc., 41, pp. 327-340, 2003.

[25] Jordan, J.L. et al., Mechanical properties of low density polyethylene. J. Dynamic Behavior Mater., 2, pp. 411-420, 2016.

[26] Omar, M.F., Akil, H.M. \& Ahmad, Z.A., Effect of molecular structures on dynamic compression properties of polyethylene. Mater. Sci. Eng., 538, pp. 125-134, 2012.

[27] Al-Salem, S.M., Abraham, G., Al-Qabandi, O.A. \& Dashti, A.M., Investigating the effect of accelerated weathering on the mechanical and physical properties of high content plastic solid waste (PSW) blends with virgin linear low density polyethylene (LLDPE). Polym. Test, 46, pp. 116-121, 2015.

[28] Al-Salem S.M., Al-Dousari, N.M., Joseph Abraham, G., Aromin D’Souza, M., AlQabandi, O.A. \& Al-Zakri, W., Effect of die head temperature at compounding stage on the degradation of linear low density polyethylene/plastic film waste blends after accelerated weathering. Int. J. Polymer Sci., 5147209, 2016.

[29] Alvarez, V.B. \& Pascall, M.A., Packaging. Encyclopedia of Dairy Sciences, ed. J.W. Fuquay, Academic Press: New York, pp. 16-23, 2011.

[30] Zhang, X., Liu, X., Zheng, W. \& Zhu, J., Regenerated cellulose/graphene nanocomposite films prepared in $\mathrm{DMAC} / \mathrm{LiCl}$ solution. Carbohydrate Polym., 88, pp. 26-30, 2012.

[31] Borse, N. \& Aubee, N., Predicting physical and optical properties of co-extruded blown films using design of experiment based model. Presented at SPE ANTEC Orlando, 2015.

[32] European Commission (EC), report from the commission to the European parliament and the council on the impact of the use of oxo-degradable plastic, including oxodegradable plastic carrier bags, on the environment, 2018. http://ec.europa.eu/ environment/circular-economy/pdf/oxo-plastics.pdf.

[33] Al-Salem, S.M., Uddin, S. \& Al-Yamani, F., An assessment of microplastics threat to the marine environment: A short review in context of the Arabian/Persian Gulf. Marine Environ. Res., 159, 104961, 2020.

[34] Al-Salem, S.M., Uddin, S. \& Lyons, B., Evidence of microplastics (MP) in gut content of major consumed marine fish species in the State of Kuwait (of the Arabian/Persian Gulf). Marine Poll. Bullt., 154, 111052, 2020.

[35] Al-Salem, S.M., Influential parameters on natural weathering under harsh climatic conditions of mechanically recycled plastic film specimens. J. Environ. Manage., 230, pp. 355-365, 2019.

[36] Al-Salem, S.M. et al., Thermal response and degressive reaction study of oxobiodegradable plastic products exposed to various degradation media. Int. J. Polym. Sci., 9612813, 2019. 